\title{
8 Ausblick
}

Das IASB scheint - nach Veröffentlichung von IFRS 9 und den damit einhergehenden Änderungen von IFRS 7 - mit den Regeln zur Bilanzierung und Offenlegung von Finanzinstrumenten wohl erstmal zufrieden zu sein. Für Nicht-Banken wesentliche Projekte mit Finanzinstrumente-Bezug findet man auf der Agenda des IASB derzeit jedenfalls nicht. Einzig ein Projekt namens „Financial Instruments with Characteristics of Equity“ lässt sich dem Themenkomplex zuordnen. Das Projekt hat die Zielsetzung, die Abgrenzung von Eigen- und Fremdkapital bei der Ausgabe von Finanzinstrumenten neu zu regeln. Insofern sind davon primär die Vorgaben in IAS 32 betroffen. Ein Discussion Paper dazu wurde bereits im Februar 2008 veröffentlicht. Ein weiteres diesbezügliches Discussion Paper hat das IASB Ende Juni 2018 publiziert. 